
\title{
28 Research Suare \\ The Reconvictions of Mentally Disordered Offenders - How, When, and Where?
}

Ebba Noland ( $\sim$ ebba.noland@umu.se )

Umeå University

Mattias Strandh

Umeå University

Fia Klötz Logan

Region Västernorrland

\section{Research Article}

Keywords: forensic psychiatry, mentally disordered offenders, criminal recidivism, reconviction

Posted Date: January 12th, 2022

DOI: https://doi.org/10.21203/rs.3.rs-1063310/v1

License: (1) This work is licensed under a Creative Commons Attribution 4.0 International License.

Read Full License

Version of Record: A version of this preprint was published at BMC Psychiatry on April 13th, 2022. See the published version at https://doi.org/10.1186/s12888-022-03912-4. 


\section{Abstract \\ Background}

Little is known about the recidivism of mentally disordered offenders after discharge from forensic psychiatric services. This is problematic because such knowledge could (i) help professionals who come into contact with this group to better plan interventions to prevent recidivism and (ii) clarify the effectiveness of forensic psychiatric care. The aim of this study was to investigate the new crimes of mentally disordered offenders who had been reconvicted after discharge from forensic psychiatric care.

\section{Methods}

Included in this study were all individuals who had been discharged from forensic psychiatric care in Sweden during 2009-2018, were included in the Swedish National Forensic Psychiatric Register, and had been reconvicted in a criminal court within the follow-up period of 2009-2018 ( $n=157)$. Retrospective registry data along with coded data from criminal judgments $(n=210)$ were used to create a database. Descriptive statistical analysis was performed.

\section{Results}

$75 \%$ of included individuals were reconvicted for at least one violent crime, but only 9 individuals were reconvicted for a serious violent crime, which can be compared to the 44 individuals with serious violent index crimes. The most common crime was "Other violent". The most common sentence was probation. The offender's most common relationship to the victim was having no known relationship, followed by the victim being a person of authority. The most common circumstance of the crime leading to the reconviction was that it occurred without apparent provocation; other common circumstances were related to the exercise of public authority. The most common crime scene was a public place.

\section{Conclusions}

Even though the reconvictions of this group included many violent crimes, there were very few serious violent crimes. The finding that the victims of the crimes of mentally disordered offenders are most commonly either unknown to the perpetrator or persons of authority, and that the crimes are often perpetrated without apparent provocation or reason, is important information for all professionals who come into contact with this group and should be taken into consideration in order to assess risk more accurately.

\section{Background}


Mental disorders, and therefore also mentally disordered offenders (MDOs), exist in all countries [1]. The Swedish Penal Code, however, differs from most others in the world since it states that mental disorders do not absolve a defendant from criminal responsibility. If the defendant who is convicted of a crime is also found to have a severe mental disorder and a need for psychiatric care at the time of the trial, they will be sentenced to forensic psychiatric care [2]. The mission of forensic psychiatric care is to improve the patient's mental health and prevent future recidivism [3]. Swedish legislation says that for a forensic psychiatric patient to be discharged from forensic psychiatric services, both the risk of relapsing into serious crime due to mental disorder and the patient's mental state and personal condition must be considered [4]. Data on post-discharge recidivism is thus essential for evaluating forensic psychiatric services, their discharge processes, and their impact on the quality of life of former patients. However, research on the nature of recidivism among former forensic psychiatric patients is scarce.

Previous studies have found that factors associated with an increased likelihood of recidivism among forensic psychiatric patients include having been convicted before being admitted to forensic psychiatric care, lower age at first conviction, and substance abuse [5-8]. Situational factors including having a trustee/limited guardian and living mainly in supported accommodation were associated with a reduced likelihood of recidivism [9].

An earlier study found that $11 \%$ of forensic psychiatric patients had re-offended within one year of discharge from forensic psychiatric care, and around $30 \%$ had been re-convicted after five years [10]. For comparative purposes, another study with a mean follow-up time of 3.2 years found that $59 \%$ of offenders had reoffended after being released from prison [11]. The rate of recidivism among MDOs is thus relatively low when compared to other offenders, suggesting that research on the recidivism of offenders in general may not be generalizable to the recidivism of MDOs. Specific studies on recidivism among MDOs following discharge from forensic psychiatric care are therefore needed.

Today, we know very little about the specifics of the recidivism perpetrated by MDOs. The Swedish National Forensic Psychiatric Register (SNFPR) has reported that of the discharged MDOs who were reconvicted within a year, $26 \%$ were convicted of violent crime, $29 \%$ for crime against property, and $45 \%$ for other crime. The SNFPR also reported violent recidivism to be the most common form of recidivism, and that reconviction for the same type of crime as the index crime (the crime for which the person was convicted to forensic psychiatric care) was more common for violent crime than for other types of crime [10]. Previous research has also shown that MDOs with severe violent index offences were less likely to reoffend than those with less serious index offences [12].

Another study identified gender differences in the patterns of reoffending of MDOs after discharge from forensic psychiatric services [13], but it was noted that its findings should be interpreted with caution due to the study's small sample size (only 13 women and 23 men in the sample reoffended). Another study on the subject included only 24 patients with reconvictions [14]; small sample sizes is a common problem in forensic psychiatric research. This is largely because the relatively small overall number of forensic 
psychiatric patients and the group's low rate of recidivism means that studies on the recidivism of MDOs often have low statistical power.

The lack of research on the subject means that we as a society do not know how, where, and against who MDOs who reoffend commit their post discharge crimes. This is problematic because such knowledge is needed to evaluate the effectiveness of forensic psychiatric care, including its impact on former patients' quality of life after discharge. Having more knowledge on this subject is also important because it would help professionals such as the police, social workers, and mental health professionals who come into contact with this group to better plan appropriate interventions and prevent future recidivism.

\section{Aim of the current study}

The aim of this study was to investigate the new crimes of MDOs who had been reconvicted after discharge from forensic psychiatric services. To this end, the following questions were asked:

- How long was the period between the discharge of the MDOs from forensic psychiatric care and their reconviction?

- For what crimes were they reconvicted?

- Were they reconvicted for the same type of crime as the crime for which they had been convicted to forensic psychiatric care (i.e., the index crime)?

- Was there any difference in seriousness between the index crime and the reconviction?

- Which sanction did they receive for the new crime?

- Who was the victim of the new crime?

- Under which circumstances was the new crime committed?

\section{Methods}

\section{Study design}

This study examined both retrospective registry data and criminal judgments. The registry data was primarily collected from the SNFPR. A database was constructed by adding data on criminal sentencing post discharge from the National Council of Crime Prevention (NCCP), information on year of birth from Statistics Sweden, and coded data from district court criminal judgments. Data from the NCCP were used to identify patients who had been reconvicted after discharge from forensic psychiatric care within the follow-up period. All of the new judgments concerning these individuals $(n=210)$ were requested separately from Sweden's district courts (of which there are 48). The judgments were read separately by one of the authors (EN) and coded.

\section{Study sample}

Included were all individuals discharged from forensic psychiatric care in Sweden during 2009-2018 who were included in the SNFPR and had been reconvicted in a criminal court during the follow-up period of 
2009-2018. At the time of the data collection, the SNFPR included $86 \%$ of all forensic psychiatric patients in Sweden [15].

The group of all patients discharged within the period consisted of 1150 individuals, 938 (82\%) men and $212(18 \%)$ women. The follow-up times of the discharged patients within the time period varied from 4 to 3644 days, ( $m=1697, M d=1685$ ). Of these, 157 individuals were reconvicted and therefore included in this study, of which $139(89 \%)$ were men and 18 (12\%) were women. For further descriptive statistics, see Table 1.

\section{Coding of judgments}

For all variables, only the information described in the judgment was coded; any variable not explicitly included in the judgment was coded as "missing".

Crime category - The crimes were categorized as violent or non-violent. The following crimes were classified as violent: homicide, manslaughter, assault and battery, arson, unlawful threats, violation of integrity, unlawful coercion, molestation, violence against an officer, robbery and sexual offenses including sexual molestation. The categories of violent and non-violent crime were then divided into subcategories. The subcategories of violent crime were lethal violence (including attempted lethal violence), sexual violence, arson, violence against an officer and other violent crime. The subcategories of non-violent crime were theft, drugs/alcohol, traffic, vandalism, and other non-violent.

Serious violent crime - Serious violent crimes were defined as homicide, manslaughter, aggravated assault, sexual offences, and arson, including attempts to commit these crimes.

Sentence - The most severe sentence in each judgment was registered. Sentences depriving the defendant of their liberty were considered the most severe, followed by conditional sentences and probation. Least severe was having to pay fines.

Relationship to victim - Individual judgments may address crimes against multiple victims. This variable measures the number of judgements in which the defendant had a given relationship to any of the victims, without counting the number of victims of each category. The categories used were: partner/expartner, family member, acquaintance, authority figure, other, no known relationship, and no victim. Coding for this variable was performed on the basis of the text of the judgment. Crimes with legal persons as victims were coded as "no known relationship"; in the judgments where "no known relationship" was registered, $26 \%$ of the victims were legal persons.

Circumstance of crime - the circumstance of the crime was defined as the situation that preceded the crime or explains in what situation the crime was committed. Because an individual judgment may address several crimes, each judgment could include several circumstances. This variable measures the number of judgments in which a given circumstance could be identified. The circumstances considered were: traffic, narcotics, weapons crime, exercise of public authority, related to victim's work (not public authority), burglary, theft/robbery not in victim's home, economic crime, social gathering, stalking, 
intimate partner violence, sexual crime, motivated by previous injustice, correction/refusal of something, no apparent provocation, and other.

Crime scene-Since an individual judgment may address multiple crimes with different crime scenes, each judgment could have several different crime scenes. This variable measures the number of judgments in which the crime was committed in a given type of location. The categories used were: public place, victim's home/vehicle, defendant's home/vehicle, third party's home/vehicle, care institution/administrative authority, from a distance, and other (which included semi-public locations such as privately-owned shops, schools, etc.). This was coded on the basis of the text of the judgment; if the judgment provided no information on the crime scene, the variable was coded as "missing".

\section{Data analysis}

Descriptive statistics including frequencies, means, and medians were calculated.

\section{Results}

\section{Background characteristics}

The group consisted of 18 women (12\%) and 139 (89\%) men. Their mean length of stay in forensic psychiatric services had been 43 months, i.e. about 3.5 years $(M d=32, S D=38)$, and they were on average 38 years old $(M d=36, S D=11)$ at the time of discharge. The follow-up time ranged from 75-3644 days $(M=2210, M d=2433)$. For $68 \%$ of them, the forensic psychiatric care had been combined with special court supervision (SCS). The index crime was most commonly a violent crime (83\%), with "Other violent" (including assault, violent threats and robbery) being the most common (61\%). The index crime was a serious crime for 44 individuals (28\%). For further descriptive background statistics, see Table 1. 
Table 1

Characteristics of mentally disordered offenders who were both discharged and reconvicted between 2009 and 2018.

\begin{tabular}{|ll|}
\hline & All $(\boldsymbol{n}=157)$ \\
\hline & $M(M d)$ \\
\hline Age at discharge & $38.03(36.00)$ \\
\hline Length of stay in forensic psychiatric services (months) & $42.60(32.37)$ \\
\hline Follow-up time (days) & $2209.81(2433.00)$ \\
\hline Men & N (\%) \\
\hline Women & $139(88.5)$ \\
\hline Index crime & $18(11.5)$ \\
\hline Serious violent & \\
\hline Non serious violent & $44(28.0)$ \\
\hline Non violent & $87(55.4)$ \\
\hline Special court supervision & $26(16.6)$ \\
\hline Diagnosis & $106(67.5)$ \\
\hline Psychosis, no PD & \\
\hline PD, no psychosis & $77(49.0)$ \\
\hline Psychosis and PD & $30(19.1)$ \\
\hline Neither psychosis nor PD & $10(6.4)$ \\
\hline History of substance abuse & $40(25.5)$ \\
\hline
\end{tabular}

The new convictions 
Table 2

Data on reconvictions post discharge from forensic psychiatric care.

\begin{tabular}{|ll|}
\hline & All ( $\boldsymbol{n = 1 5 7 )}$ \\
\hline Time from discharge to new conviction (months) & $34(27)$ \\
\hline Number of crimes/person during follow-up & $3.8(2)$ \\
\hline Number of victims in judgment & $2.4(1)$ \\
\hline Number of convictions during follow-up & $1.4(1)$ \\
\hline Reconvicted for any violent crime & $\mathrm{N}(\%)$ \\
\hline Reconvicted for any serious violent crime & $118(75.2)$ \\
\hline
\end{tabular}

In total, $157 \mathrm{MDOs}$ were reconvicted within the follow-up period; see Table 2 for descriptive statistics about the reconvictions and Table 3 for information on the crimes giving rise to the reconvictions. There were 210 new judgments relating to these individuals; while most $(73 \%)$ were convicted only once during the follow-up period, $17 \%$ had been convicted twice and $7 \%$ had been convicted 3-7 times. No-one had been convicted more than 7 times within the follow-up period. Individual judgments may address multiple crimes; in total, the judgments addressed 573 crimes. On average, each MDO was convicted of 4 crimes $(M d=2)$. Most of the group, 118 individuals $(75 \%)$, had committed at least one violent crime. However, only nine MDOs ( $8 \%$ of those who had committed a new violent crime, $6 \%$ of all who were reconvicted) were reconvicted for a serious violent crime.

\section{Type of crime}


Table 3

Types of crime leading to reconvictions post

discharge from forensic psychiatric care.

\begin{tabular}{|ll|}
\hline & $\begin{array}{l}\text { All }(\boldsymbol{n}=573) \\
n(\%)\end{array}$ \\
\hline Violent crimes & $7(1.2)$ \\
\hline Lethal violence & $9(1.6)$ \\
\hline Sexual & $4(.7)$ \\
\hline Arson & $60(10.5)$ \\
\hline Violence against an officer & $184(32.1)$ \\
\hline Other violent & \\
\hline Non-violent crimes & $84(14.7)$ \\
\hline Theft & $60(10.5)$ \\
\hline Drugs/alcohol & $51(8.9)$ \\
\hline Traffic & $28(4.9)$ \\
\hline Vandalism & $86(15.0)$ \\
\hline Other non-violent & \\
\hline
\end{tabular}

Table 3 shows that the most common crime was "Other violent" (32\% of all crimes), which included assault, threats of violence, and robbery. This was followed by "Other non-violent" (15\% of all crimes), which included crimes against public activity, illegal carrying/possession of a weapon or knife, and supplementary penal provisions outside the Penal code. Also common were theft ( $15 \%$ of all crimes), violence against an officer ( $10 \%$ of all crimes), and drug/alcohol-related offences ( $10 \%$ of all crimes).

\section{Sentence}


Table 4

The sentences for reconvictions post discharge from forensic psychiatric care*.

\begin{tabular}{|c|c|c|}
\hline & $\begin{array}{l}\text { All }(n=210) \\
n(\%)\end{array}$ & $\begin{array}{l}\text { Violent crime }(n=149) * * \\
n(\%)\end{array}$ \\
\hline \multicolumn{3}{|l|}{ Sentence } \\
\hline Forensic psychiatric care & $65(30.0)$ & $56(37.6)$ \\
\hline Prison & $60(27.7)$ & $37(24.8)$ \\
\hline Probation & $76(35.0)$ & $46(30.9)$ \\
\hline Conditional sentence & $16(7.4)$ & $10(6.7)$ \\
\hline \multicolumn{3}{|c|}{$\begin{array}{l}\text { * values shown in the table are the number of judgments including the indicated sentence and (in } \\
\text { parentheses), this number as a percentage of all judgments included in the study. Note that one } \\
\text { judgment may address multiple crimes. }\end{array}$} \\
\hline \multicolumn{3}{|c|}{$\begin{array}{l}\text { ** values shown in the table are the number of judgments pertaining to violent crime including the } \\
\text { indicated sentence and (in parentheses), this number as a percentage of all judgments included in the } \\
\text { study. }\end{array}$} \\
\hline
\end{tabular}

The sentences assigned during the reconvictions are shown in Table 4. The most common sentences were probation (35\%), forensic psychiatric care (30\%) and prison (28\%). For judgments pertaining to at least one violent crime, the most common sentences were forensic psychiatric care (38\%), probation (31\%), and prison (25\%).

\section{Victims}


Table 5

The perpetrator's relationship to the victim for reconvictions post discharge from forensic psychiatric care*.

\begin{tabular}{|lll|}
\hline & $\begin{array}{l}\text { All }(\boldsymbol{n}=\mathbf{2 1 0}) \\
n(\%)\end{array}$ & $\begin{array}{l}\text { Violent crime }(\boldsymbol{n}=\mathbf{1 4 9}) * * \\
\boldsymbol{n}(\%)\end{array}$ \\
\hline Partner/ex-partner & $21(11.5)$ & $21(14.1)$ \\
\hline Family member & $20(11.5)$ & $20(13.4)$ \\
\hline Acquaintance & $41(23.5)$ & $38(25.5)$ \\
\hline Authority figure & $59(31.2)$ & $56(37.6)$ \\
\hline Other & $2(1.3)$ & $1(0.7)$ \\
\hline No known relationship & $105(45.9)$ & $72(48.3)$ \\
\hline No victim & $34(17.2)$ & $2(1.3)$ \\
\hline $\begin{array}{l}\text { * values shown in the table are the number of judgments including the indicated sentence and (in } \\
\text { parentheses), this number as a percentage of all judgments included in the study. Note that one } \\
\text { judgment may address multiple crimes. }\end{array}$ \\
\hline $\begin{array}{l}\text { ** values shown in the table are the number of judgments pertaining to violent crime including the } \\
\text { indicated sentence and (in parentheses), this number as a percentage of all judgments included in the } \\
\text { study. }\end{array}$ \\
\hline
\end{tabular}

In total, 376 victims were registered in all judgments. Of these 157 (42\%) were male, $142(38 \%)$ were female, and $76(20 \%)$ were legal persons. The number of victims in the judgments ranged from 0 to 18 ( $M$ $=2.4, M d=1)$. For judgments addressing at least one violent crime, there were in total 305 victims. Of these 139 (46\%) were male, $124(41 \%)$ were female, and 42 (14\%) were legal persons.

The most common relationship to the victim in all judgments was no known relationship (46\%), followed by the victim being a person of authority (31\%), an acquaintance (24\%), and the crime being victimless $(17 \%)$. It should be noted that for the sentences where "no known relationship" was registered, 50 of the 190 victims (26\%) were legal persons.

In judgments addressing violent crimes, no known relationship was most common (48\%), followed by the victim being an authority figure (38\%) and the victim being an acquaintance (26\%). For further information on the relationships between perpetrators and victims, see Table 5.

\section{Circumstance of crime}


Table 6

Circumstances of crimes leading to reconvictions post discharge from forensic psychiatric services*.

\begin{tabular}{|c|c|c|}
\hline & $\begin{array}{l}\text { All }(n=210) \\
n(\%)\end{array}$ & $\begin{array}{l}\text { Violent crime }(n=149) \star * \\
n(\%)\end{array}$ \\
\hline Traffic & $17(8.3)$ & $3(2)$ \\
\hline Narcotics & $23(12.7)$ & $5(3.4)$ \\
\hline Weapon's crime & $4(2.5)$ & $1(0.7)$ \\
\hline Exercise of public authority & $49(27.4)$ & $47(31.5)$ \\
\hline Related to victim's work, not public authority & $9(5.7)$ & $8(5.4)$ \\
\hline Burglary & $20(10.8)$ & $7(4.7)$ \\
\hline Theft/robbery, not in victim's home & $47(24.2)$ & $19(12.8)$ \\
\hline Economic crime & $5(3.2)$ & $0(0)$ \\
\hline Social gathering & $12(7.0)$ & $12(8.1)$ \\
\hline Stalking & $6(3.8)$ & $6(4)$ \\
\hline Intimate partner violence & $18(10.2)$ & $18(12.1)$ \\
\hline Sexual crime & $7(3.8)$ & $7(4.7)$ \\
\hline Previous injustice & $17(9.6)$ & $16(10.7)$ \\
\hline Correction/refusion of something & $10(6.4)$ & $10(6.7)$ \\
\hline No apparent provocation & $62(33.8)$ & $58(38.9)$ \\
\hline Other & $9(4.3)$ & $7(4.7)$ \\
\hline \multicolumn{3}{|c|}{$\begin{array}{l}\text { * values shown in the table are the number of judgments including the indicated sentence and (in } \\
\text { parentheses), this number as a percentage of all judgments included in the study. Note that one } \\
\text { judgment may address multiple crimes. }\end{array}$} \\
\hline \multicolumn{3}{|c|}{$\begin{array}{l}\star \star \text { values shown in the table are the number of judgments pertaining to violent crime including the } \\
\text { indicated sentence and (in parentheses), this number as a percentage of all judgments included in the } \\
\text { study. }\end{array}$} \\
\hline
\end{tabular}

The most common circumstance of crime across all judgments was no apparent provocation (34\%), followed by exercise of public authority $(27 \%)$, and theft or robbery occurring in a location other than the victim's living accommodation (24\%). Other common circumstances were burglary (11\%), intimate partner violence $(10 \%)$, and revenge for some previous injustice $(10 \%)$. 
For judgments addressing violent crime(s), the most common circumstance was no apparent provocation $(39 \%)$, followed by exercise of public authority $(32 \%)$ and theft or robbery occurring in a location other than the victim's living accommodation (13\%). Other common circumstances were intimate partner violence $(12 \%)$, previous injustice $(11 \%)$, social gathering $(8 \%)$, and correction or refusal of something (7\%). For more detailed information, see Table 6.

\section{Crime scene}

Table 7

The crime scenes for crimes leading to reconviction post discharge from forensic psychiatric care*.

\begin{tabular}{|c|c|c|}
\hline & $\begin{array}{l}\text { All }(n=210) \\
n(\%)\end{array}$ & $\begin{array}{l}\text { Violent crime }(n=149) * * \\
n(\%)\end{array}$ \\
\hline Public place & $90(42.3)$ & $64(43)$ \\
\hline Victim's home/vehicle & $50(23.8)$ & $38(25.5)$ \\
\hline Defendant's home/vehicle & $22(10.4)$ & $20(13.4)$ \\
\hline Third party's home/vehicle & $10(4.8)$ & $9(6)$ \\
\hline Care institution/administrative authority & $29(13.8)$ & $26(17.4)$ \\
\hline Other (e.g. Privately owned shops) & $68(32.4)$ & $42(28.2)$ \\
\hline From a distance & $27(12.9)$ & $18(12.1)$ \\
\hline \multicolumn{3}{|c|}{$\begin{array}{l}\text { * values shown in the table are the number of judgments including the indicated sentence and (in } \\
\text { parentheses), this number as a percentage of all judgments included in the study. Note that one } \\
\text { judgment may address multiple crimes. }\end{array}$} \\
\hline \multicolumn{3}{|c|}{$\begin{array}{l}\star \star \text { values shown in the table are the number of judgments pertaining to violent crime including the } \\
\text { indicated sentence and (in parentheses), this number as a percentage of all judgments included in the } \\
\text { study. }\end{array}$} \\
\hline
\end{tabular}

The most common crime scene in all judgments was a public place (42\%). This was followed by "other" (32\%), which included semi-public locations such as privately-owned shops. Other common crime scenes were the victim's home/vehicle (24\%), an institution/administrative authority (14\% of judgments), and from a distance (13\%). For judgments containing at least one violent crime, the most common crime scene was a public place (43\%), "other" (28\%) and victim's home or vehicle (26\%). Other common crime scenes were an institution/administrative authority (17\%) and the defendant's home or vehicle $(13 \%)$, see Table 7.

\section{The index crime and the reconviction}


Table 8

Number of mentally disordered offenders reconvicted for violent/non-violent crime.

\begin{tabular}{|lll|}
\hline & $\begin{array}{l}\text { Reconviction } \\
\text { Non-violent, (\%) }\end{array}$ & $\begin{array}{l}\text { Reconviction } \\
\text { Violent, any } \\
(\%), \text { of which serious (\%) }\end{array}$ \\
\hline $\begin{array}{l}\text { Index crime } \\
\text { Non-violent }(n=26)\end{array}$ & $15(58), \mathbf{0}(\mathbf{0})$ \\
\hline $\begin{array}{l}\text { Index crime } \\
\text { Violent, not serious }(n=87)\end{array}$ & $61(70)$ & $69(79), \mathbf{5}(\mathbf{6})$ \\
\hline $\begin{array}{l}\text { Index crime } \\
\text { Serious violent }(n=44)\end{array}$ & $29(66)$ & $34(77), 4(9)$ \\
\hline Total $(n=157)$ & $110(70)$ & $118(75), 9(6)$ \\
\hline
\end{tabular}

Table 8 shows how many individuals with violent/non-violent index crimes were reconvicted for violent/non-violent crimes. In total, 26 individuals had been convicted for a non-violent index crime. Twenty (77\%) of these people were subsequently reconvicted for a non-violent crime, 15 (58\%) were convicted for a non-serious violent crime, and none were convicted for a serious violent crime. Eightyseven individuals had been convicted for a non-serious violent index crime, of whom 61 (70\%) were later reconvicted for a non-violent crime, 69 (79\%) were reconvicted for a non-serious violent crime, and 5 (6\%) were reconvicted for a serious violent crime. Forty-four individuals had been convicted for a serious violent index crime, of whom 29 (66\%) were later reconvicted for a non-violent crime, 34 (77\%) were reconvicted for a non-serious violent crime, and $4(9 \%)$ were reconvicted for a serious violent crime.

\section{Discussion}

The aim of this study was to investigate the new crimes of MDOs who had been reconvicted after discharge from forensic psychiatric care. No attempt was made to identify factors differing between MDOs who were reconvicted post discharge and those who were not. The group of MDOs who are reconvicted after discharge from forensic psychiatric services consists mainly of men. Typically, they are in their late thirties at the time of discharge, have a violent index crime and a history of substance abuse, and have been diagnosed with some form of psychosis. The full group of patients discharged from forensic psychiatric care during the studied period shares these characteristics, although the reconvicted individuals as a group were slightly younger at the time of discharge [9]. It should also be noted that most of the MDOs discharged during this period (86\%) were not reconvicted. 
Most of the reconvicted individuals had one new conviction during the follow-up period, but it was common for individual judgments to address multiple new crimes. Most of the group had been reconvicted for at least one violent crime and at least one non-violent crime. However, the proportion of serious violent crimes was significantly lower for the reconvictions than for the index crimes. This indicates that even when this group reoffended, their criminality was generally less severe than before receiving forensic psychiatric care. The conclusion that recidivism was less serious overall than the index crimes is supported by the fact that the most common sentence in all judgments was probation (see Table 4). The high rate of probation may also reflect the high frequency of substance abuse in the group, because Swedish law allows probationary sentences to be combined with compulsory treatment for substance-related disorders [16].

If only judgments addressing at least one violent crime are considered (149 of the 210 judgments), most of the above remains true. The relative frequencies of the different relationships between perpetrators and victims were similar, and the different circumstances (aside from those relating specifically to thefts) were roughly as common as in the full set of judgments. However, among judgments for violent crimes, sentences to forensic psychiatric care were more common, fewer victims were legal persons, and the crime scene was more often a care institution or administrative authority and more rarely categorized as "other" (which often meant semi-public places such as privately owned shops).

\section{Acts of madness?}

The most commonly observed circumstance of crime was "No apparent provocation", and the most common relationship between the MDO and their victim was having no known relationship, followed by the victim being some kind of authority figure. Even though "no known relationship" includes crimes with legal persons as the victim, the majority of crimes in this group were not committed against legal persons. These facts support the stereotypical image of acts of madness perpetrated by mentally disordered individuals that is commonly presented in the media and was summarized well by FE Markowitz [17], who described how the high publicity surrounding certain violent events has generated misunderstandings concerning the risk of violence and a perception of mental illness that overemphasizes violence. However, the real crimes committed by MDOs after discharge from forensic psychiatric care are generally less serious than the stereotype suggests. This is important because it has also been shown that imprisonment does not reduce recidivism [18] and that an individual's number of convictions is associated with an increase in seriousness of crime [19]. It has been also been reported that while the rate of stranger perpetrators differs between types of crime, only a third of all violent crime is perpetrated by strangers [20]. The higher rate of stranger perpetrators shown in this study strengthens the assumption that MDOs are a group requiring further study.

The high frequency of crimes against persons of authority also highlights situations of increased risk that may need to be considered by forensic psychiatric services before discharging a patient. It is also something that professionals of different kinds should be aware of when coming into contact with MDOs, along with the fact that reconvicted MDOs with a violent index crime are more likely to be 
reconvicted for a violent crime than those with a non-violent index crime. This is supported by previous research showing that a history of violence is a very important risk factor for future violence [21]. It is possible that providing training specifically in dealing with MDOs and pre-discharge training of MDOs to prepare for such situations could reduce the number of crimes against this group.

Another notable finding is the relatively high frequency of crimes involving some sort of (perceived) previous injustice or refusal. This could be an issue for forensic psychiatric services to address before discharge, which could be done both by investigating whether there is someone in particular the patient holds a grudge towards and by focusing interventions on how the patient handles perceived injustices and refusals.

\section{The assessments leading to discharge}

It should be noted that when evaluating a patient for discharge from forensic psychiatric care combined with SCS, one factor that must be considered by the court or chief medical officer is the risk of relapsing into serious crime. The fact that much of the recidivism of MDOs seems to involve minor offenses and the rarity of serious crimes suggests that this aspect of the system works quite well. The effectiveness of the current system (possibly including both the forensic psychiatric care that is provided and the procedure for discharging patients) is also supported by the fact that the overall recidivism rate of MDOs is low when compared to that of former prisoners overall [10,11]. However, the reasons for this and the influence of forensic psychiatric care on the rate of recidivism are unclear, particularly since previous studies on offenders referred to pre-trial psychiatric investigations have revealed no significant differences between individuals sentenced to forensic psychiatric treatment, prison, or noncustodial sanctions [5].

\section{New forensic psychiatric care - a sign of not taking prescribed medication?}

The second most common sentence among the studied MDOs was committal to forensic psychiatric care, indicating that these individuals were once again assessed as needing inpatient forensic psychiatric care. This is not entirely surprising since psychoses generally persist throughout life and would not have been cured by the previous forensic psychiatric care. However, research on whether these patients' mental states had worsened because they had stopped taking their prescribed medication since discharge would be highly interesting.

\section{Limitations}

A limitation of this study was the fact that Swedish criminal judgments vary widely in terms of the detail they provide about the circumstances of the crime. This affected the coding process, making it impossible in some cases to determine which circumstances applied or whether the perpetrator and victim knew one-another. As a result, some data were categorized as "missing". However, the sample size is still considerably larger than those of previous studies on recidivism among MDOs. 


\section{Conclusion}

Although the reconvictions of this group included many violent crimes, there were very few serious violent crimes. The goal of the forensic psychiatric services is obviously to prevent reconvictions entirely, but it seems that at least the reconvictions of MDOs are generally for crimes less serious than the index crimes.

The finding that the victims of the MDOs' crimes are most often unknown to the perpetrator, and that the crimes are often perpetrated without apparent provocation or reason is important information for all professionals who come into contact with this group. Furthermore, it was found that persons of authority quite frequently become victims when exercising their authority, which should be taken into consideration when planning security measures.

\section{Abbreviations}

MDO - Mentally disordered offender

SCS - Special court supervision

SNFPR - Swedish National Forensic Psychiatric Register

NCCP - National Council of Crime Prevention

\section{Declarations}

\section{Ethics approval and consent to participate}

Ethical approval for the research was given by the regional ethical review board in Umeå, dnr 2018/22231 , and supplemental ethical approval was given by the Swedish National Ethical Review Authority (the approval of dual review boards was related to a reorganization after the first ethical approval, creating a National Authority instead of several smaller regional boards), dnr 2019-05055. Administrative permissions from the SNFPR were then required to access the register data. All methods were carried out in accordance with relevant guidelines and regulations, and all individuals included in the SNFPR had been informed about their right to, at any time, opt-out of the register. The data was anonymized before its use.

\section{Consent for publication}

Not applicable.

\section{Availability of data and materials}


The data that support the findings of this study are available from SNFPR but restrictions apply to the availability of these data, which were used under license for the current study, and so are not publicly available. Data are however available from the authors upon reasonable request and with permission of SNFPR.

\section{Competing interests}

The authors declare that they have no competing interests.

\section{Funding}

No funding was received.

\section{Authors' contributions}

All authors provided final approval of the submitted manuscript and agree to be accountable for all aspects of the work in ensuring that questions related to the accuracy or integrity of any part of the work are appropriately investigated and resolved. EN is responsible for study conception, literature review, analysis of data, interpretation of the data, and drafting the manuscript. MS and FKL are responsible for interpretation of the data and critical revisions.

\section{Acknowledgements}

Not applicable.

\section{References}

1. World Health Organization: The world health report 2001: mental health : new understanding, new hope. Geneva: World Health Organization; 2001.

2. Svennerlind C, Nilsson T, Kerekes N, Andiné P, Lagerkvist M, Forsman A, Anckarsäter $H$, Malmgren $H$ : Mentally disordered criminal offenders in the Swedish criminal system. International Journal of Law and Psychiatry 2010, 33(4):220-226.

3. National Board of Health and Welfare: Psykiatrisk tvångsvård och rättspsykiatrisk vård. Handbok med information och vägledning för tillämpningen av Socialstyrelsens föreskrifter och allmänna råd om psykiatrisk tvångsvård och rättspsykiatrisk vård (SOSFS 2008:18). In. Edited by Welfare NBoHa. Västerås: Edita Västra Aros AB; 2009.

4. Compulsory Psychiatric Care Act [https://www.riksdagen.se/sv/dokument-lagar/dokument/svenskforfattningssamling/lag-19911129-om-rattspsykiatrisk-vard_sfs-1991-1129] 
5. Lund C, Hofvander B, Forsman A, Anckarsäter H, Nilsson T: Violent criminal recidivism in mentally disordered offenders: A follow-up study of 13-20 years through different sanctions. International Journal of Law and Psychiatry 2013, 36(3-4):250-257.

6. Bonta $\mathrm{J}$, Blais $\mathrm{J}$, Wilson HA: A theoretically informed meta-analysis of the risk for general and violent recidivism for mentally disordered offenders. Aggression and Violent Behavior 2014, 19(3):278-287.

7. Coid J, Hickey N, Kahtan N, Zhang T, Yang M: Patients discharged from medium secure forensic psychiatry services: reconvictions and risk factors. Br J Psychiatry 2007, 190(3):223-229.

8. Krona H, Nyman M, Andreasson H, Vicencio N, Anckarsäter H, Wallinius M, Nilsson T, Hofvander B: Mentally disordered offenders in Sweden: differentiating recidivists from non-recidivists in a 10-year follow-up study. Nordic Journal of Psychiatry 2017, 71(2):102-109.

9. Noland E, Strandh M: Factors associated with post discharge recidivism in forensic psychiatric patients - a Swedish registry study. International Jounal of Law and Psychiatry 2021, forthcoming.

10. Swedish National Forensic Pychiatric Register: Annual report 2020. In. Gothenburg: Swedish National Forensic Psychiatric Register; 2020.

11. Fazel S, Chang Z, Fanshawe T, Långström N, Lichtenstein P, Larsson H, Mallett S: Prediction of violent reoffending on release from prison: derivation and external validation of a scalable tool. The Lancet Psychiatry 2016, 3(6):535-543.

12. Charette Y, Crocker AG, Seto MC, Salem L, Nicholls TL, Caulet M: The National Trajectory Project of Individuals Found Not Criminally Responsible on Account of Mental Disorder in Canada. Part 4: Criminal Recidivism. The Canadian Journal of Psychiatry 2015, 60(3):127-134.

13. Alm C, Berman AH, Kristiansson M, Lindqvist P, Palmstierna $T$, Gumpert $\mathrm{CH}$ : Gender differences in reoffending among psychiatrically examined Swedish offenders. Criminal behaviour and mental health 2010, 20(5):323-334.

14. Björk T, De Santi MG, Kjellin L: Criminal recidivism and mortality among patients discharged from a forensic medium secure hospital. Nordic Journal of Psychiatry 2012, 66(4):283-289.

15. Swedish National Forensic Psychiatric Register: Annual report 2018. In. Gothenburg: Swedish National Forensic Psychiatric Register; 2018.

16. Sanctions [https://www.kriminalvarden.se/swedish-prison-and-probation-service/sanctions/]

17. Markowitz FE: Mental illness, crime, and violence: Risk, context, and social control. Aggression and Violent Behavior 2011, 16(1):36-44.

18. Cullen FT, Jonson CL, Nagin DS: Prisons Do Not Reduce Recidivism: The High Cost of Ignoring Science. The Prison journal (Philadelphia, Pa) 2011, 91(3_suppl):48S-65S.

19. Liu J, Francis B, Soothill K: A Longitudinal Study of Escalation in Crime Seriousness. Journal of quantitative criminology 2011, 27(2):175-196.

20. Rand MR: Criminal victimization, 2008. In.: U.S. Department of Justice; 2009.

21. Douglas KS, Hart SD, Webster CD, Belfrage H: HCR-20 V3. Assessing risk for violence.. Burnaby: Mental Health, Law, and Policy Institute, Simon Fraser University; 2013. 